Cite this: RSC Adv., 2017, 7, 52024
Check for updates

\section{Modulating molecular structures and dielectric transitions in organic-inorganic hybrid crystals $\uparrow$}

\author{
Xiao-Fen Sun, Zhongxia Wang, (DD* Wei-Qiang Liao, (D) Peng-Fei Li, Jixing Gao, \\ Yi-Yang Huang, Hai-Peng Chen, Heng-Yun Ye and Yi Zhang (DD *
}

In this paper, three new hybrid phase transition compounds, $\left[\mathrm{Hmpy}_{\mathrm{CdBr}}\right.$ (1, Hmpy $=\mathrm{N}$ methylpyrrolidinuium cation), $\left[\mathrm{Hmpy}_{2} \mathrm{CdBr}_{4}\right.$ (2) and $[\mathrm{Hmpy}]_{3} \mathrm{CdBr}_{3} \cdot \mathrm{CdBr}_{4}$ (3), were synthetized by means of regulating the ratio of reactants. Systematic characterizations consisting of variable temperature $\mathrm{X}$-ray single crystal diffraction, differential scanning calorimetry (DSC) and dielectric measurements reveal that 1 with infinite one-dimensional (1D) $\left[\mathrm{CdBr}_{3}\right]_{n}{ }^{-}$chains undergoes a phase transition around $278 \mathrm{~K}$; 2 with isolated $\left[\mathrm{CdBr}_{4}\right]^{2-}$ tetrahedrons exhibits a high-temperature phase transition close to $367 \mathrm{~K}$, accompanied by prominent switchable dielectric behavior. Interestingly, $1 \mathrm{D}\left[\mathrm{CdBr}_{3}\right]_{n}{ }^{-}$chains and isolated $\left[\mathrm{CdBr}_{4}\right]^{2-}$ tetrahedrons both exist in 3, associated with a phase transition at $320 \mathrm{~K}$. The phase transitions in the three compounds are originated from the order-disorder transitions of the Hmpy cation. It is expected that our finding would promote the development of hybrid dielectric transition materials with adjustable properties.

Received 25th September 2017 Accepted 21st October 2017

DOI: 10.1039/c7ra10616e

rsc.li/rsc-advances

to their readily self-assembling. ${ }^{10,11}$ At the same time, studies of organic-inorganic hybrid has also been extended to phase transition materials. ${ }^{12-14}$ Structurally, the organic components located in the gaps of the inorganic metal skeletons possess large freedom of motion (e.g. reorientation/frozen transitions).$^{15}$ The dynamic components are responsive to the external stimuli such as temperature, light, pressure, electric and magnetic fields, etc. ${ }^{16}$ resulting in structural phase transition accompanied by some interesting physical properties ${ }^{17-21}$ In this case, the dielectric properties might be tuned through the modulation of organic cations in organic-inorganic hybrid phase transition materials. ${ }^{2-25}$ For example, a series of metal-formate A $\left[\mathrm{Mg}(\mathrm{HCOO})_{3}\right] \quad(\mathrm{A}=$ organic ammonium cation $),\left[\mathrm{NH}_{4}\right]$ $\left[\mathrm{Mg}(\mathrm{HCOO})_{3}\right], \quad\left[\mathrm{CH}_{3} \mathrm{CH}_{2} \mathrm{NH}_{3}\right]\left[\mathrm{Mg}(\mathrm{HCOO})_{3}\right]$, and $\left[\mathrm{NH}_{3}\left(\mathrm{CH}_{2}\right)_{4^{-}}\right.$ $\left.\mathrm{NH}_{3}\right]\left[\mathrm{Mg}_{2}(\mathrm{HCOO})_{6}\right]$ display dielectric transitions at 255, 374, and $412 \mathrm{~K}$, respectively. ${ }^{26}$ The approaches of replacing organic cations achieve the regulation of dielectric transitions from low temperature to high temperature, as well as the dielectric responsive characteristics. Besides, the regulation of dielectric properties can also be achieved by the control of inorganic frameworks., ${ }^{5,27}$ For instance, B-site of metal-formate system $\left[\mathrm{NH}_{2} \mathrm{NH}_{3}\right]\left[\mathrm{B}(\mathrm{HCOO})_{3}\right]\left(\mathrm{B}=\mathrm{Mn}^{2+}, \mathrm{Zn}^{2+}, \mathrm{Co}^{2+}\right.$ and $\left.\mathrm{Mg}^{2+}\right)$ undergo dielectric responses at $350 \mathrm{~K}(\mathrm{Mn}$ and $\mathrm{Zn}), 380 \mathrm{~K}(\mathrm{Co})$ and $348 \mathrm{~K}$ $(\mathrm{Mg})$, respectively. ${ }^{5}$ Therefore, some practical and promising dielectric properties could be obtained by substituting components within the similar structures. But the reports of controlling dielectric responses in completely different inorganic frameworks resulted from the modulation of ratio of the reactants are very scarce.

Herein, the present work has been reported structural phase transitions and dielectric responses in three hybrids, [Hmpy] 
$\mathrm{CdBr}_{3}$ (1), $[\mathrm{Hmpy}]_{2} \mathrm{CdBr}_{4}$ (2) and $\left[\mathrm{Hmpy}_{3} \mathrm{CdBr}_{3} \cdot \mathrm{CdBr}_{4}\right.$ (3), which were synthetized by the stoichiometric regulation of same reactants (Scheme 1). These three organic-inorganic hybrid compounds with completely different molecular structures display controllable structural phase transitions and dielectric responses: 1 with $1 \mathrm{D}$ chains experiences a dielectric phase transition at $278 \mathrm{~K}, 2$ with isolated tetrahedrons shows a switchable dielectric anomaly at about $367 \mathrm{~K}$ and 3 with integrated geometry undergoes a phase transition at $320 \mathrm{~K}$, achieving the regulation of phase transition temperatures and dielectric behaviors. Systematic characterization reveals that the order-disorder transitions of Hmpy cations lead to the phase transitions coupled with striking dielectric behavior in the three compounds.

\section{Experimental}

\section{Synthesis}

All chemicals were purchased from Aladdin and without further purification. Clear colorless crystals of 1, 2 and 3 were synthesized by slow evaporation of the $\mathrm{HBr} / \mathrm{H}_{2} \mathrm{O}(40 \%$, w/w) solution containing Hmpy hydrobromide and $\mathrm{CdBr}_{2} \cdot 4 \mathrm{H}_{2} \mathrm{O}$ with the molar ratio of $1: 1,2: 1$ and $3: 2$ after a few weeks, respectively (Fig. S1, ESI $\dagger$ ). Phase purities of 1, 2 and 3 in the form of polycrystalline samples were confirmed by powder X-ray diffraction (PXRD) measurements, in which the experimental patterns match well with the simulated ones (Fig. S2-S4, ESI $\dagger$ ). Infrared (IR) spectra show the strong vibration peak in the three compounds at around $3100 \mathrm{~cm}^{-1}$, indicating the presence of $\mathrm{R}_{3} \mathrm{~N}^{+} \mathrm{H}$ (Fig. S5, ESI $\dagger$ ). TGA measurements reveal that the samples of 1, 2 and 3 are stable below about $560 \mathrm{~K}$ (Fig. S6, ESI $\dagger$ ).

\section{Single-crystal X-ray crystallography}

Variable-temperature X-ray single-crystal diffraction data for the single crystals of 1, 2 and 3 were collected on a Rigaku Saturn $724^{+}$diffractometer with Mo-K $\alpha$ radiation $(\lambda=0.71073 \AA)$. All the structures were solved using direct methods and refined by the full-matrix method based on $F^{2}$ by means of the SHELXLTL software package. ${ }^{28}$ The non-hydrogen atoms were refined anisotropically using all reflections with $I>2 \sigma(I)$. The carbonbound $\mathrm{H}$ atoms were added geometrically and refined using the riding model with $U_{\text {iso }}=1.2 U_{\text {eq }}(\mathrm{C}$ and $\mathrm{N})$. As to 2 , the structure at $373 \mathrm{~K}$ was refined in $P \overline{3}$ with high $R$ factors, resulting from the poor crystal quality after long exposure at

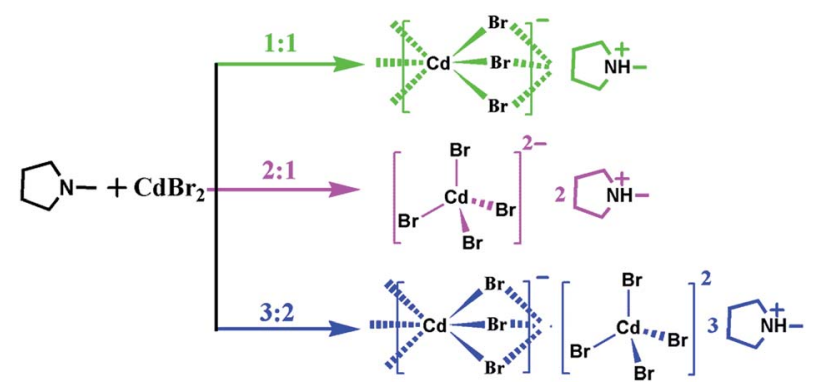

Scheme 1 The synthetic routes of 1, 2 and 3 . high temperature. Crystallographic data and details of the three compounds are summarized in Table S1, (ESI $\dagger$ ).

\section{Thermal measurements}

Thermogravimetric analysis was recorded on a DSC/DTA-TG SDT-Q600 instrument at the rate of $10 \mathrm{~K} \mathrm{~min}^{-1}$ under nitrogen atmosphere from room temperature to $800 \mathrm{~K}$. Differential scanning calorimetry (DSC) was performed on a PerkinElmer Diamond DSC instrument by heating and cooling the polycrystalline samples with a rate of $10 \mathrm{~K} \mathrm{~min}^{-1}$ in aluminum crucibles under nitrogen at atmospheric pressure.

\section{Dielectric measurements}

The dielectric permittivity toward 1, 2 and $\mathbf{3}$ were measured on a Tonghui TH2828A instrument at selected frequencies in the corresponding temperature range. The measuring AC voltage was $1 \mathrm{~V}$. The powder-pressed pellets and single crystal sample deposited with silver conducting glue were used in dielectric measurements.

\section{Results and discussion}

\section{Thermal properties}

DSC measurements were performed to study the phase transitions in 1, 2 and 3. As plotted in Fig. 1, thermal anomaly peaks were detected at 273/278 K for 1, 340/367 K for 2 and 315/320 K for 3 in cooling and heating runs. Such results demonstrate a reversible phase transition in 1 at $273 \mathrm{~K}$ (below the room temperature), in 2 at $367 \mathrm{~K}$ and in 3 at $320 \mathrm{~K}$ (above the room temperature), respectively. Moreover, the observed thermal hysteresis ( $5 \mathrm{~K}$ for $\mathbf{1}$ and $27 \mathrm{~K}$ for 2 ) and obvious $\lambda$-type peak reveal the feature of discontinuous first-order in the process of phase transitions. ${ }^{\mathbf{4} 7-10}$ The broad peaks in $\mathbf{3}$ with a hysteresis of $5 \mathrm{~K}$ indicates a weak first-order type of phase transition. It is noted that the phase transition point $\left(T_{\mathrm{c}}\right)$ of 2 is approximately $97 \mathrm{~K}$ higher than 1 and about $47 \mathrm{~K}$ higher than 3 . The obvious changes of $T_{\mathrm{c}}$ in the three compounds illustrate that their phase transition properties have been adjusted through the

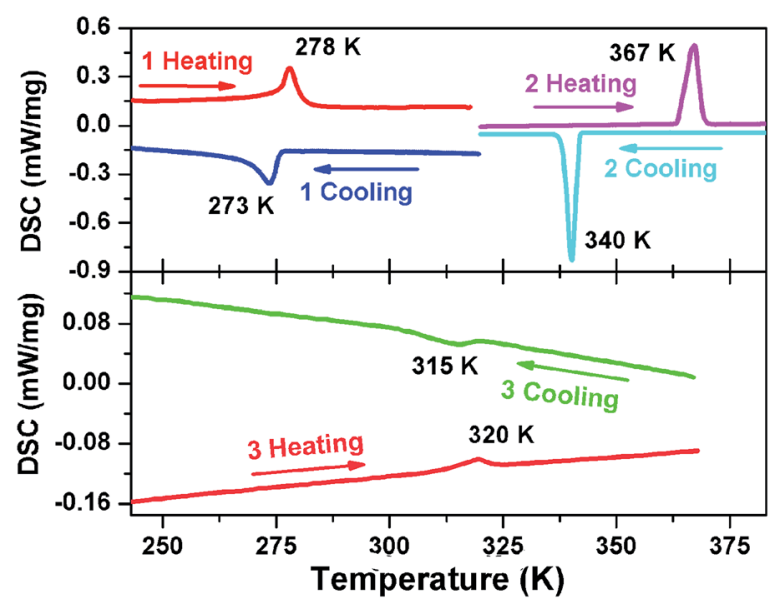

Fig. 1 DSC curves of 1 (a), 2 (b) and 3 (c). 
modification of molecular structures (Scheme 1), achieving the regulation of $T_{\mathrm{c}}$ in a wide temperature range. In addition, the $\Delta S$ $\left(\mathrm{J} \mathrm{mol}^{-1} \mathrm{~K}^{-1}\right)$ for phase transitions in the heating process of $\mathbf{1 , 2}$ and 3 were estimated approximately 3.146, 0.813 and 0.472 , respectively. Based on the Boltzmann equation $\Delta S=R \ln (N), R$ being the gas constant, the ratio of respective geometrically distinguishable orientations $N(\mathbf{1}), N(\mathbf{2})$ and $N(3)$ are calculated to be 1.46, 1.10 and 1.06, respectively. For convenience, the phases above $273 \mathrm{~K}(\mathbf{1}), 367 \mathrm{~K}(2)$ and $320 \mathrm{~K}(3)$ are assigned as the high-temperature phase (HTP), and the phase below $273 \mathrm{~K}$ (1), $340 \mathrm{~K}$ (2) and $315 \mathrm{~K}$ (3) as the low-temperature phase (LTP).

\section{Crystal structures}

The crystal structure of $\mathbf{1}$ has a hexagonal perovskite-type structure, containing infinite chains of face-sharing $\mathrm{CdBr}_{6}$ octahedrons, which are comparable to some reported one dimensional perovskite-type hybrids, such as $\left[\mathrm{C}_{3} \mathrm{H}_{4} \mathrm{NS}\right]\left[\mathrm{CdBr}_{3}\right] .^{29}$ 1 crystallizes in the orthorhombic space group Pnma (no. 62) at $293 \mathrm{~K}$ (HTP). The asymmetric unit in the HTP consists of one independent Hmpy cation, three $\mathrm{Cd}$ atoms, and six $\mathrm{Br}$ atoms, where the Hmpy cation is divided equally by the $m$ plane (101) (Fig. 2a). The face-sharing $\mathrm{Cd}$ octahedrons with $\mathrm{Cd}-\mathrm{Br}$ distances ranging from 2.771 (1) to 2.806 (1) $\AA$ and adjacent $\mathrm{Br}-\mathrm{Cd}-\mathrm{Br}$ angles varying from $83.63(5)^{\circ}$ to $180^{\circ}$ (Table S2, ESI $\dagger$ ) form onedimensional chains along the crystallographic $b$-axis, in which the Hmpy cations occupy the cavities between the adjacent chains (Fig. S7, ESI $†$ ). Upon cooling to $263 \mathrm{~K}$ (LTP), the inorganic configuration of $\mathbf{1}$ is similar to that in the HTP. But the crystal structure was solved in the space group $P 2_{1} / c$ (no. 14). The relationship of the cell unit is $b^{263 \mathrm{~K}} \approx a^{293 \mathrm{~K}}$ and $a^{263 \mathrm{~K}} \approx b^{293 \mathrm{~K}}$ (Table S1, ESI $\dagger$ ). The molecular structure of LTP is composed of an independent Hmpy cation, three $\mathrm{Cd}$ atoms, and nine $\mathrm{Br}$ atoms, accompanied by the absence of mirror plane. Moreover, the Hmpy cation is clearly ordered than that in the HTP (Fig. 2b).

Compound 2 contains an independent monomeric $\left[\mathrm{CdBr}_{4}\right]^{2-}$ anion and two crystallographically independent Hmpy cations (Fig. $2 \mathrm{c}$ and d). In the HTP, 2 crystallizes in the centrosymmetric orthorhombic space group Pbca (no. 61). The value of $\mathrm{Br}-\mathrm{Cd}-\mathrm{Br}$ angles belonging to $\left[\mathrm{CdBr}_{4}\right]^{2-}$ anion vary from $104.74(2)^{\circ}$ to $113.11(2)^{\circ}$ and the $\mathrm{Cd}-\mathrm{Br}$ distances range from 2.554 (4) to 2.615 (5) $\AA$ (Table S3, ESI $\dagger$ ), leading to a weak distortion of tetrahedrons. As the temperature decreased to the LTP, the inorganic skeleton of 2 is almost unchanged compared to that in the HTP (Table S3, ESI $\dagger$ ). It is noted that the Hmpy cations can be described in two parts (A and B). In the HTP, A and B molecules are all strongly disordered. Moreover, the atoms of A molecule are almost in a plane (Fig. 2c). Whereas, the Hmpy cation experiences great changes in the LTP, in which the $\mathrm{N}$ atom of A part occupies two symmetric sites and the two Hmpy cations are more ordered than those in the HTP (Fig. 2d). In addition, the organic cations have hydrogen-bonding interactions with the inorganic chains through $\mathrm{N}-\mathrm{H} \cdots \mathrm{Br}$ hydrogen bonds with the donoracceptor distances of 3.491(1) $\AA$, contributing to a threedimensional hydrogen bond network (Table S4 and Fig. S8, ESI†).

Interestingly, compound 3 consists of monomeric $\left[\mathrm{CdBr}_{4}\right]^{2-}$ anions, infinite $\left[\mathrm{CdBr}_{3}\right]_{n}{ }^{-}$chains and independent Hmpy cations

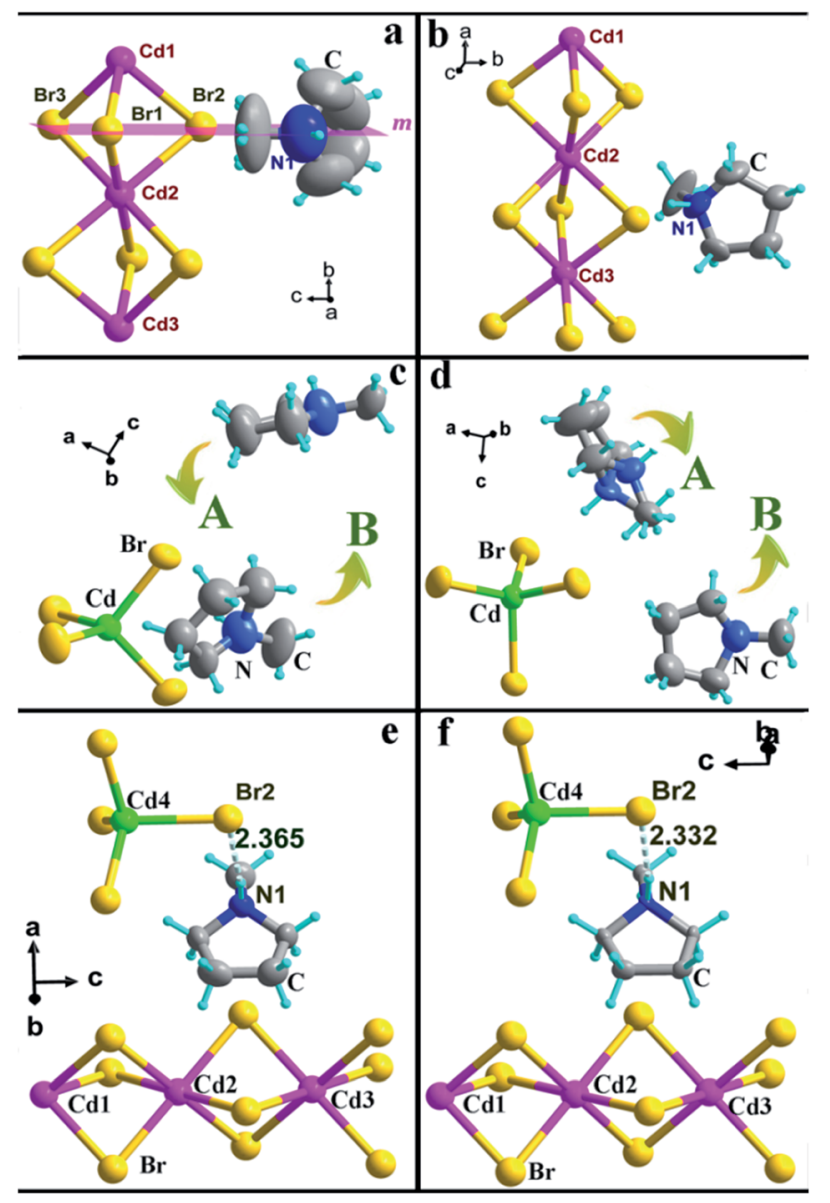

Fig. 2 Molecular structures of 1 at $293 \mathrm{~K}$ (a) and $263 \mathrm{~K}$ (b). Molecular structures of 2 at $373 \mathrm{~K}$ (c) and $293 \mathrm{~K}$ (d). Molecular structures of 3 at $343 \mathrm{~K}(\mathrm{e})$ and $253 \mathrm{~K}$ (f). The dashed lines denote the $\mathrm{N}-\mathrm{H} \cdots \mathrm{Br}$ interactions. Thermal ellipsoids for all atoms are shown at $30 \%$ probability level.

(Fig. 2e and f). The crystal structures of 3 in the HTP and LTP both crystallize in trigonal space group $P \overline{3}$ and the inorganic frameworks regarding $\left[\mathrm{CdBr}_{3}\right]^{-}$and $\left[\mathrm{CdBr}_{4}\right]^{2-}$ anions are comparable to those in 1 and $\mathbf{2}$ (Table S5, ESI $\dagger$ ). The cell parameters of HTP and LTP show slightly different (Table S1 ESI†), but the thermal ellipsoids of Hmpy are obviously larger than those in the LTP (Fig. 2e and f). As shown in Fig. S9 (ESI†), each $\mathrm{N}$ atom of the Hmpy bearing an extra proton that forms hydrogen-bonding interaction toward a $\mathrm{Br}$ atom belonging to a $\left[\mathrm{CdBr}_{4}\right]^{2-}$ anion with the distance of $\mathrm{N}-\mathrm{H} \cdots \mathrm{Br} 2.332 \AA$ (HTP) and $2.365 \AA$ (LTP), respectively (Table S6, ESI $\dagger$ ). Then, it seems like that three Hmpys and an independent $\left[\mathrm{CdBr}_{4}\right]^{2-}$ anion as a whole fills in the blank between the inorganic chains along the $c$-axis.

\section{Dielectric properties}

The temperature dependence of the real part $\left(\varepsilon^{\prime}\right)$ of the complex dielectric permittivity at several selected frequencies is shown in Fig. 3. For 1, there is a pair of anomalies at $1000 \mathrm{kHz}$ in the vicinity of $273 \mathrm{~K}$ in a cooling and heating run, indicating a reversible dielectric transition (Fig. 3a). Upon cooling, the $\varepsilon^{\prime}$ 
slowly decreases to $\mathrm{ca}$. 14 with the decreasing of temperature from 310 to $275 \mathrm{~K}$. Then $\varepsilon^{\prime}$ occurs a turning point at $273 \mathrm{~K}$ and goes on decreasing slowly to offer a inconspicuous step-like type dielectric anomaly. The unstable dielectric value before and after the phase transition point demonstrates the competition between external electric field induced orientational polarization and temperature triggered dynamic motion of the Hmpy cation. ${ }^{30}$ Moreover, as the frequency decreases, the anomaly around $273 \mathrm{~K}$ is gradually obvious with the larger changes of the $\varepsilon^{\prime}$, revealing the $\varepsilon^{\prime}$ is strongly frequency dependent (Fig. 3b). As to the imaginary part $\varepsilon^{\prime \prime}$, there is a pair of wide peaks close to $273 \mathrm{~K}$ in a cooling and heating run $(1000 \mathrm{kHz})$, confirming the reversible phase transition in 1 (Fig. S10a, ESI†). Also, the $\varepsilon^{\prime \prime}$ demonstrates slightly frequency dependence in that the maximum value of $800 \mathrm{kHz}$ is greater than that of $1000 \mathrm{kHz}$. In combination of structural analyses, the dielectric transition in 1 is in virtue of the order-disorder transition of the Hmpy cation.

For 2, temperature dependent $\varepsilon^{\prime}$ was measured in the temperature range of $325-380 \mathrm{~K}$ at $1000 \mathrm{kHz}$ are drawn in Fig. 3c, where $\varepsilon^{\prime}$ exhibits an remarkable step-like dielectric behavior. In the heating process, the $\varepsilon^{\prime}$ remains stable at $c a .10$ (low-dielectric state) below $364 \mathrm{~K}$. Then the $\varepsilon^{\prime}$ shows a sharp rise close to 23.5 (high-dielectric state) followed by an approximately 2 times as high as that in the LTP. The large thermal hysteresis during the heating and cooling process (ca. $25 \mathrm{~K}$ ) and the remarkable dielectric switching make 2 a promising energy storage and switchable dielectric material. Also, the $\varepsilon^{\prime}$ of 2 shows the prominent frequency dependence. The $\varepsilon^{\prime}$ at lower frequencies increases quickly accompanied by the decreasing of measured frequencies (Fig. 3d), and the $\varepsilon^{\prime \prime}$ is similar to $\varepsilon^{\prime}$ with
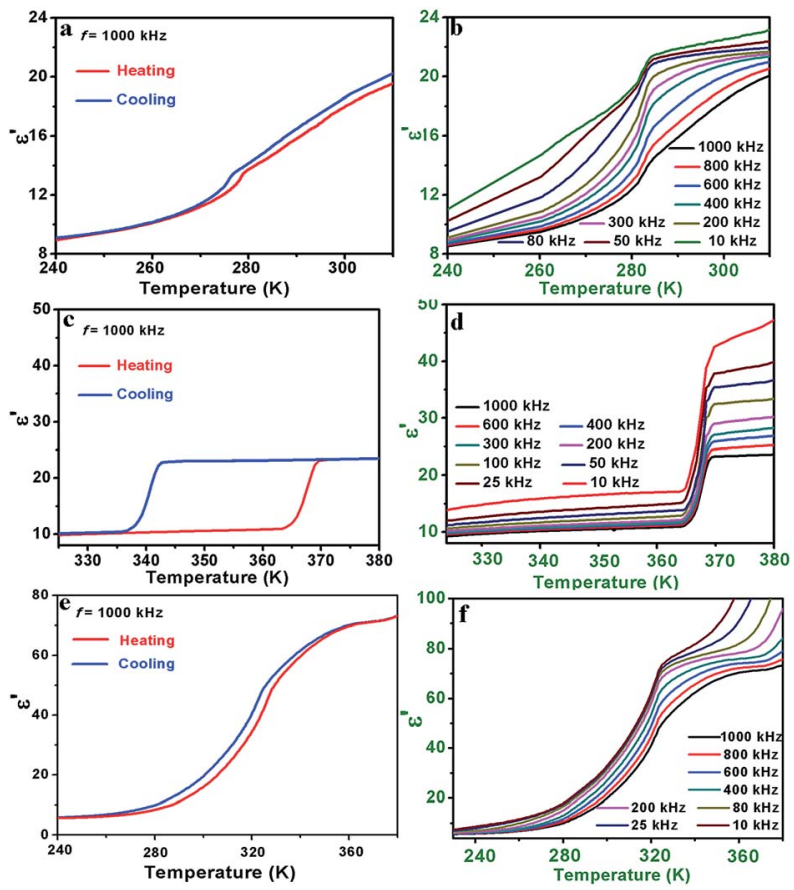

Fig. 3 The temperature-dependence of the real part $\left(\varepsilon^{\prime}\right)$ measured at $1000 \mathrm{kHz}$ and selected frequencies of the polycrystalline sample of 1 (a and b), 2 (c and d) and 3 (e and f). strongly frequency dependence (Fig. S10b, ESI $\dagger$ ). The thermal hysteresis observed in the curve of $\varepsilon^{\prime \prime}(c a .27 \mathrm{~K})$ is accordance with the real part and the result of DSC measurement. Based on the single crystal structures of 2 , the Hmpy cations are strongly disordered in the HTP. As the temperature decreased to the LTP, the Hmpy cations change to be relative ordered. ${ }^{31,32}$ Therefore, the dielectric responses of 2 are originated from the dynamic motions of the organic cations.

For 3, there is a general change in the curve of $\varepsilon^{\prime}$ around $320 \mathrm{~K}$ (Fig. 3e). In the HTP above $360 \mathrm{~K}$, the $\varepsilon^{\prime}$ keeps a value of $c a$. 70. And then, the $\varepsilon^{\prime}$ slowly decreases to 6 with the temperature cooling to around $240 \mathrm{~K}$ in the LTP. Moreover, the dependence of frequency also can be observed in the curve of $\varepsilon^{\prime}$ in the range of $10 \mathrm{kHz}-1000 \mathrm{kHz}$ (Fig. 3f). The unstable dielectric behaviors
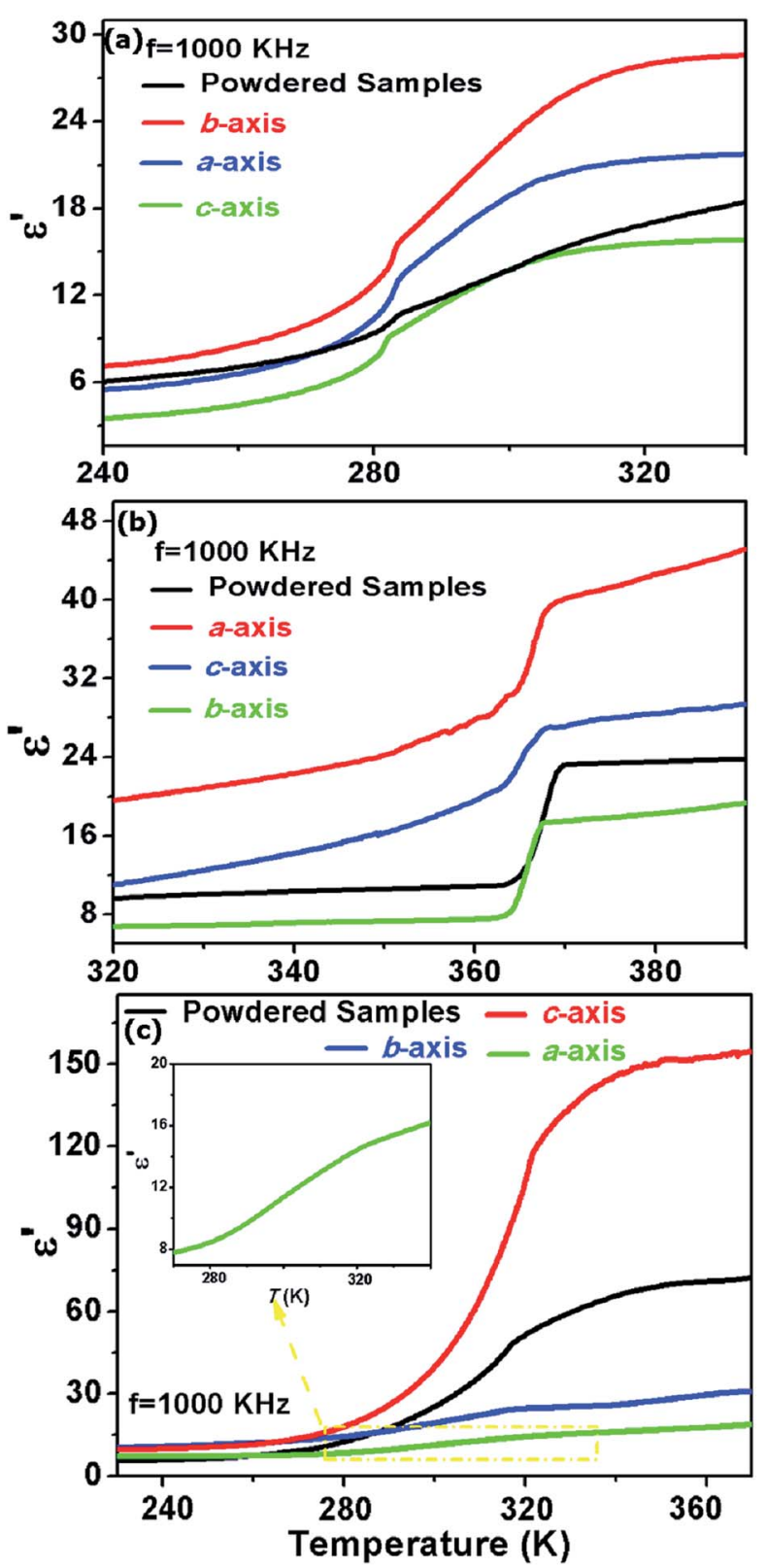

Fig. 4 The temperature-dependence of the real part $\left(\varepsilon^{\prime}\right)$ of $1(a), 2(b)$ and 3 (c) measured on crystal samples along the $a-, b$ - and $c$-axes. 
in the HTP and LTP are similar to those in 1, indicating the competition between the thermal motion and polarization of organic cations. The imaginary part $\varepsilon^{\prime \prime}$ shows broad peaks in the process of phase transition around $320 \mathrm{~K}$ (Fig. S10c, ESI $\dagger$ ).

Therefore, the features of the dielectric responses of 1, 2 and 3 can be addressed by the orientational transitions of the Hmpy cations between the HTP and LTP. In the HTP, the organic cations demonstrate dynamic motions. As the temperature decreased in the LTP, the motions of cations are frozen. ${ }^{33}$ In addition, the difference in phase transition temperature and the dielectric behaviors in the three compounds is due to the various inorganic anionic frameworks, leading to the different dynamic motions of the Hmpy cations. ${ }^{11 c}$

The dielectric anisotropy measurements of 1, 2 and 3 were performed on the crystal samples, respectively. As shown in Fig. $4 \mathrm{a}$, the $\varepsilon^{\prime}$ of 1 in the HTP along the $b$ - and $a$-axes are larger than that in the powdered samples, but the $\varepsilon^{\prime}$ along the $c$-axis is the smallest one. Based on the structural analyses, the rotation motions of the Hmpy cations in the $a b$-plane may be responsible for the dielectric anisotropy in 1. In 2, step-like dielectric anomalies are observed around $367 \mathrm{~K}$ along the different crystallographic directions. Moreover, the $\varepsilon^{\prime}$ along the $a$ - and $c$-axes are larger than that in the direction of $b$-axis. The anisotropy can be explained that the reorientationally disordered Hmpy cations in 2 settled in the $a c$-plane will result in the motions along $a$-and $c$-axes. In 3 , the $\varepsilon^{\prime}$ along the $c$-axis is remarkably greater than those along the $a$-and $b$-axes. It can be illustrated that the Hmpy cations in $\mathbf{3}$ are located in the planes parallel to $c$-axis and the reorientational motions of Hmpy cations will give the largest contribution to the dielectric anomaly along the $c$-axis.

\section{Conclusions}

In this work, three new controllable structural cadmiumbromate compounds have successfully synthesized by regulating the ratio of reactants. Compound $\mathbf{1}$ is comprised of the $\left[\mathrm{CdBr}_{3}\right]_{n}{ }^{-}$chains and the Hmpy cations occupied the space of the adjacent chains. The isolated $\left[\mathrm{CdBr}_{4}\right]^{2-}$ tetrahedrons and the Hmpy cations are alternated in 2. Interestingly, 3 shows novel structure, containing $\left[\mathrm{CdBr}_{3}\right]_{n}{ }^{-}$chains, isolated $\left[\mathrm{CdBr}_{4}\right]^{2-}$ tetrahedrons and Hmpy cations filled in the interval of inorganic frameworks. In the diverse molecular structures of the three hybrid compounds, the order-disorder transitions of the Hmpy cations, which are responsive to the temperature, contribute to the adjustable dielectric responses. 1 displays a phase transition at $c a .273 \mathrm{~K} .2$ shows a promising switchable dielectric behavior approximately at 367 K. 3 undergoes a phase transition $\mathrm{ca} .320 \mathrm{~K}$. Given that the reported hybrid structures here are easily prepared and tuned, our finding is expected to provide new impetus to construct new functional materials showing controllable structures with adjustable properties based on organic-inorganic hybrids.

\section{Conflicts of interest}

There are no conflicts to declare.

\section{Acknowledgements}

This work was supported by the National Key Research and Development Program of China (Grant 2017YFA0204803), the National Natural Science Foundation of China (21522101, 21371032), the Outstanding Young Teachers of Southeast University Research Fund (Grant 2242015R30025, 2242017K41027), and the Scientific Research Foundation of Graduate School of Southeast University (YBJJ1629).

\section{Notes and references}

1 (a) Z. R. Grabowski, K. Rotkiewicz and W. Rettig, Chem. Rev., 2003, 103, 3899-4032; (b) P. P. Shi, Y. Y. Tang, P. F. Li, W. Q. Liao, Z. X. Wang, Q. Ye and R. G. Xiong, Chem. Soc. Rev., 2016, 45, 3811-3827; (c) Y. Morita, T. Murata and K. Nakasuji, Bull. Chem. Soc. Jpn., 2013, 86, 183-197.

2 (a) W. Zhang, H. Y. Ye, R. Graf, H. W. Spiess, Y. F. Yao, R. Q. Zhu and R. G. Xiong, J. Am. Chem. Soc., 2013, 135, 5230-5533; (b) H. Y. Ye, S. H. Li, Y. Zhang, L. Zhou, F. Deng and R. G.Xiong, J. Am. Chem. Soc., 2014, 136, 10033-10040; (c) Y. Imai, B. Zhou, Y. Ito, H. Fijimori, A. Kobayashi, Z. M. Wang and H. Kobayashi, Chem.-Asian J., 2012, 7, 2786-2790.

3 (a) X.-H. Lv, W.-Q. Liao, Z.-X. Wang, P.-F. Li, C.-Y. Mao and H.-Y. Ye, Cryst. Growth Des., 2016, 16, 3912-3916; (b) P. Li, X. Yang, T. W. Mass, J. Hanss, M. Lewin, A. K. Michel, M. Wuttig and T. Taubner, Nat. Mater., 2016, 15, 870-875.

4 Y. Zhang, H.-Y. Ye, W. Zhang and R.-G. Xiong, Inorg. Chem. Front., 2014, 1, 118.

5 S. Chen, R. Shang, K. L. Hu, Z. M. Wang and S. Gao, Inorg. Chem. Front., 2014, 1, 83-98.

6 B. Orayech, L. Ortega-San-Martin, I. Urcelay-Olabarria, L. Lezama, T. Rojo, M. I. Arriortua and J. M. Igartua, Dalton Trans., 2016, 45, 14378-14393.

7 Y.-L. Liu, Y.-F. Wang and W. Zhang, CrystEngComm, 2016, 18, 1958-1963.

8 W. Zhang, Y. Cai, Y. R. G. Xiong, H. Yoshikawa and K. Awaga, Angew. Chem., Int. Ed., 2010, 49, 6608-6610.

9 Z. X. Wang, W. Q. Liao, H. Y. Ye and Y. Zhang, Dalton Trans., 2015, 44, 20406-20412.

10 (a) H. P. Chen, Z. X. Wang, C. Chen, Y. Lu, Z. Yin, X. F. Sun and D. W. Fu, Dalton Trans., 2017, 46, 4711-4716; (b) A. Sieradzki, S. Pawlus, S. N. Tripathy, A. Gagor, M. Ptak, M. Paluch and M. Maczka, Dalton Trans., 2017, 46, 36813687; (c) R. Valiente, M. C. Marco de Lucas, J. I. Espeso and F. Rodriguez, Solid State Commun., 1993, 86, 663-666.

11 (a) Y. Zhang, W. Q. Liao, D. W. Fu, H. Y. Ye, Z. N. Chen and R. G. Xiong, J. Am. Chem. Soc., 2015, 137, 4928-4931; (b) Y. Zhang, W. Q. Liao, D. W. Fu, H. Y. Ye, C. M. Liu, Z. N. Chen and R. G. Xiong, Adv. Mater., 2015, 27, 39423946; (c) X. F. Sun, Z. Wang, P. F. Li, W. Q. Liao, H. Y. Ye and Y. Zhang, Inorg. Chem., 2017, 56, 3506-3511.

12 (a) P. Jain, N. S. Dalal, B. H. Toby, H. W. Kroto and A. K. Cheetham, J. Am. Chem. Soc., 2008, 130, 10450-10451; (b) P. Jain, V. Ramachandran, R. J. Clark, H. D. Zhou, 
B. H. Toby, N. S. Dalal, H. W. Kroto and A. K. Cheetham, J. Am. Chem. Soc., 2009, 131, 13625-13627.

13 A. Piecha, A. Białońska, R. Jakubas and W. Medycki, Solid State Sci., 2008, 10, 1469-1479.

14 (a) Z. Cui, K. Gao, C. Liu, Y. Yin, D.-W. Fu, H.-L. Cai and X. S. Wu, J. Phys. Chem. C, 2016, 120, 2925-2931; (b)

T. Khan, M. A. Asghar, Z. Sun, A. Zeb, L. Li, L. Sijie, S. Zhao, C. Ji and J. Luo, Chem.-Asian J., 2016, 11, $2876-2881$.

15 (a) W. Zhang, H.-Y. Ye and R.-G. Xiong, Coord. Chem. Rev., 2009, 253, 2980-2997; (b) Z. X. Wang, P. F. Li, W. Q. Liao, Y. Tang, H. Y. Ye and Y. Zhang, Chem.-Asian J., 2016, 11, 981-985.

16 (a) R. Ramesh, Nature, 2009, 461, 1218-1219; (b) M. Wuttig and N. Yamada, Nat. Mater., 2007, 6, 824-832.

17 (a) M. Salinga and M. Wuttig, Science, 2011, 332, 543-544; (b) S. Zhang, J. Zhao, P. Ma, J. Niu and J. Wang, Chem.-Asian J., 2012, 7, 966-974.

18 F. M. Raymo, Adv. Mater., 2002, 14, 401-414.

19 C. Ji, Z. Sun, S. Q. Zhang, T. Chen, P. Zhou, Y. Tang, S. Zhao and J. Luo, J. Mater. Chem. C, 2014, 2, 6134-6139.

20 M. N. Tchoul, S. P. Fillery, H. Koerner, L. F. Drummy, F. T. Oyerokun, P. A. Mirau, M. F. Durstock and R. A. Vaia, Chem. Mater., 2010, 22, 1749-1759.

21 W. Fu and T. Nakamura, Biosci., Biotechnol., Biochem., 2017, 81, 839-847.

22 K. Gao, M. Gu, X. Qiu, X. N. Ying, H. Y. Ye, Y. Zhang, J. Sun, X. Meng, F. M. Zhang and D. Wu, J. Mater. Chem. C, 2014, 2, 9957-9963.

23 J.-Z. Ge, X.-Q. Fu, T. Hang, Q. Ye and R.-G. Xiong, Cryst. Growth Des., 2010, 10, 3632-3637.
24 P. Zhou, Z. Sun, S. Zhang, C. Ji, S. Zhao, R. G. Xiong and J. Luo, J. Mater. Chem. C, 2014, 2, 2341-2345.

25 Y.-Z. Tang, Z.-F. Gu, J.-B. Xiong, J.-X. Gao, Y. Liu, B. Wang, Y.-H. Tan and Q. Xu, Chem. Mater., 2016, 28, 4476-4482.

26 R. Shang, G. C. Xu, Z. M. Wang and S. Gao, Chem.-Eur. J., 2014, 20, 1146-1158.

27 (a) W.-J. Xu, K.-P. Xie, Z.-F. Xiao, W.-X. Zhang and X.-M. Chen, Cryst. Growth Des., 2016, 16, 7212-7217; (b) Y. Zhang, W.-Q. Liao, H.-Y. Ye, D.-W. Fu and R.-G. Xiong, Cryst. Growth Des., 2013, 13, 4025-4030; (c) Q. Ye, T. Akutagawa, N. Hoshino, T. Kikuchi, S. Noro, R. G. Xiong and T. Nakamura, Cryst. Growth Des., 2011, 11, 4175-4182; (d) Z. Sun, J. Luo, T. Chen, L. Li, R. G. Xiong, M. L. Tong and M. Hong, Adv. Funct. Mater., 2012, 22, 4855-4861.

28 G. M. Sheldrick, SHELX-97, Program for Crystal Structure Determination, University of Göttingen, Germany, 1997.

29 W. Q. Liao, H. Y. Ye, Y. Zhang and R. G. Xiong, Dalton Trans., 2015, 44, 10614-10620.

30 X. D. Shao, X. Zhang, C. Shi, Y. F. Yao and W. Zhang, Adv. Sci., 2015, 1500029.

31 S. Thies, H. Sell, C. Schütt, C. Bornholdt, C. Näther, F. Tuczek and R. Herges, J. Am. Chem. Soc., 2011, 133, 16243-16250.

32 A. Piecha, A. Gągor, M. Węcławik, R. Jakubas and W. Medycki, Mater. Res. Bull., 2013, 48, 151-157.

33 (a) W. Q. Liao, G. Q. Mei, H. Y. Ye, Y. X. Mei and Y. Zhang, Inorg. Chem., 2014, 53, 8913-8918; (b) D. W. Fu, W. Zhang, H. L. Cai, Y. Zhang, J. Z. Ge, R. G. Xiong, S. D. Huang and T. Nakamura, Angew. Chem., Int. Ed., 2011, 50, 11947-11951. 